\title{
EVALUATION OF BIS(IMINO)PYRIDINE IRON CATALYST ON HETEROGENEOUS ETHYLENE POLYMERIZATION
}

\author{
Suellem B. Cordeiro ${ }^{1}$, Maria de Fátima V. Marques ${ }^{1, 凶}$
}

https://doi.org/10.23939/chcht14.02.185

\begin{abstract}
This work deals with synthesis, characterization and evaluation of post-metallocene complexes based on silica-supported bis(imino)pyridine iron, containing amino groups in ethylene polymerizations. The reaction of these complexes and methylaluminoxane generated active species in heterogeneous ethylene polymerization. The absence of substituents at the orthoposition of the phenyl rings near the metal site was not compensated by the steric hindrance of the silica surface, negatively affecting the catalytic activity and the molar mass of the produced polymer. The catalyst $\mathrm{C} 1$, with the most bulkier ligand, presented the best performance, showing high catalytic activity not only in homogeneous system, but also in supported systems due to the chemical bond between the functionalized complex and the support surface, which led to polyethylene particles with good morphology, spherical tendency, filled pores and the decrease in bulk density compared to the particles produced through homogeneous catalyst.
\end{abstract}

Keywords: ethylene polymerization, supported catalyst, silica, bis(imino)pyridine catalyst.

\section{Introduction}

In the 1990s, the interest in complexes of transition metals has led to the rise of a very large and diversified research field [1-3]. Coordination compounds with ligand structures different from those found in metallocene catalysts, which comprise cyclopentadienyl $(\mathrm{Cp})$ rings, resulted in the advent of the so-called post-metallocene catalysts, revolutionizing the world of polyolefin.

Due to problems arising from the homogeneous nature of the polymers production process, these catalysts easily lead to an extremely exothermic polymerization process and could result in serious fouling of the reactor in the slurry process of olefin polymerization. Thus, the application of these catalysts in a continuous process was

\footnotetext{
${ }^{1}$ Universidade Federal do Rio de Janeiro,

Instituto de Macromoléculas Eloisa Mano, IMA-UFRJ,

Cidade Universitária. Av. Horácio Macedo, 2.030

Centro de Tecnologia, Bloco J, Rio de Janeiro, RJ. Brasil

\fmarques@ima.ufrj.br

(C) Cordeiro S., Marques M., 2020
}

difficult. In general, the way to solve these problems is to immobilize the catalysts on suitable carriers. This heterogenization enables control of polyolefins morphology. Controlling particle growth eliminates reactor fouling and produces polymer particles with shapes that mirror those of the starting catalyst particles [3-6].

Studies have been described dealing with the heterogenization of single-site catalysts. They mainly consider the use of inorganic-based supports such as silica, alumina, zeolites, magnesium chloride or the use of methods to immobilize single-site catalysts (either inside or at the surface of linear or cross-linked polymers) generally polystyrene (PS) or polysiloxane-based organic supports [7-11]. Among several materials used as support in homogeneous catalysts, the silica stands out, since it has a high specific area and can fragment during olefins polymerization.

Heterogenization can improve the stability of catalytic sites, preventing rapid decay of the polymerization rate observed for many catalyst systems. Thus, the development of supported catalysts greatly benefits from remarkable progress made in the development of silica-supported single site catalysts. Because covalent anchoring of catalysts on silica is rather tedious, few efforts have been made in industry to apply such catalysts. The literature shows same alternatives synthetic strategy, for example, the immobilization of the activator prior to addition of the transition metal complex, among others [12].

Lee et al. [13] studied the effect of mesoporous silica functionalization (SBA-15) with various organosilane compounds having amine, nitrile or imidazoline groups, carried out via post-synthesis grafting method, on the syntheses of supported single-site system based on ( $n$ $\mathrm{BuCp})_{2} \mathrm{ZrCl}_{2}$ and MAO in the ethylene polymerization. Interestingly, the metal contents in the prepared supported catalysts were strongly dependent on the nitrogen content at the functionalized support, due to the strong interaction between the metallocene compound and amine or nitrile groups on the mesoporous silica surface. The polymerization activities of $(n-\mathrm{BuCp})_{2} \mathrm{ZrCl}_{2}$ supported on NS or NCy-functionalized SBA-15 increased along with the nitrogen and $\mathrm{Zr}$ contents of the supported catalyst. 
The main purpose of the present study is the synthesis of new post-metallocene heterogeneous systems using complexes directly on partially supported on hydroxylated silica, as well as the evaluation of the catalytic performance in ethylene polymerization, comparing the activity of the prepared supported catalysts and the properties of the synthesized polyethylene with those resulting from the homogeneous counterpart. Therefore, bis(imino)pyridine iron complex having amine group was applied for post-synthesis grafting on silica surface to prepare the supported single-site catalysts. The effect of $\mathrm{NH}_{2}$-functionalized complex for the immobilization was investigated in ethylene polymerization using methylaluminoxane as cocatalyst.

\section{Experimental}

All manipulations of air- and/or moisture-sensitive compounds were routinely performed under an inert atmosphere using a glove box and/or standard Schlenk techniques.

\subsection{Materials}

The silica, MS3050 was provided by PQ Corporation (USA).

Methylaluminoxane (MAO) was purchased from Crompton Corporation, Germany, in a toluene solution with concentration of $1.9 \mathrm{M}$. Toluene (Ipiranga petrochemical, commercial purity) was distilled over sodium/ benzophenone ketyl prior to use.

Ethylene was supplied by White Martins Gases Industrial, purity $99.9 \%$, eluted in columns $3 \mathrm{~A}$ molecular sieve and copper catalyst. All other starting materials were commercially available and were used without further purification.

\subsection{Homogeneous Systems}

Homogeneous solutions of different bis(imino) pyridine iron complexes in toluene were prepared and $0.005 \mathrm{mmol} \mathrm{Fe}$ was directly employed in the ethylene polymerization reactions [14]. All polymerization reactions were performed in a 11 Büchi glass reactor equipped with a mechanical stirrer, connected to a thermostatic system. In a typical polymerization experiment, the autoclave was charged with $100 \mathrm{ml}$ toluene and the system was charged with ethylene up to the desired concentration, the appropriate amount of the complex and MAO (mixed previously together) at the temperature of $323 \mathrm{~K}$. The mechanical stirrer was run with $600 \mathrm{rpm}$ for all experiments to avoid diffusion-controlled polymerizetion reactions. Molar ratios were varied between $\mathrm{Al} /$ transition metal $(100,200$ or 2000) and the pressures of ethylene in the reaction medium $\left(2 \cdot 10^{5}\right.$ or $\left.4 \cdot 10^{5} \mathrm{~Pa}\right)$. After the desired polymerization time $(60 \mathrm{~min})$, the polymer- rization was stopped by quenching with ethanol containing 5\% HCl. Polymers were dried overnight at $333 \mathrm{~K}$, washed with $5 \% \mathrm{HCl}$ in ethanol solution and further with methanol for several times until total clean of the supernatant and dried again to constant weight.

\subsection{Heterogeneous System}

\subsubsection{Silica pretreatment}

The support was pre-prepared (calcination, for removal of excess hydroxyl groups) to be reacted with the post-metallocene compound, without pre-treatment with aluminum alkyl. The preparation of the supported catalyst was carried out a few moments before the polymerization reaction in the reaction medium (in situ).

The calcination was performed as previously described in the literature [8]. The silica was calcined from room temperature to reach $723 \mathrm{~K}$, with the heating rate of $5 \mathrm{~K} / \mathrm{min}$, under nitrogen flow of $80 \mathrm{ml} / \mathrm{min}$. The silica remained for $4 \mathrm{~h}$ at $723 \mathrm{~K}$, under constant nitrogen flow. After that, the material was slowly cooled down to room temperature at the same nitrogen flow.

After thermal pretreatment, the silica was transferred to Schlenk glass and stored under vacuum. This material was used directly to the fixation of the catalyst on the support surface and it was subsequently added to the reactor to conduce the ethylene polymerization.

\subsubsection{Direct supporting of the homogeneous post-metallocene catalyst on silica surface}

Iron catalyst solution in toluene was prepared to make it react with pretreated silica $(0.05 \mathrm{mmol} \mathrm{Fe} / \mathrm{g}$ silica $)$ in a Schlenk flask under vigorous stirring for $24 \mathrm{~h}$. After the immobilization, the heterogeneous catalyst was washed three times with $30 \mathrm{ml}$ of toluene each time, at room temperature, and dried until no weight loss was observed.

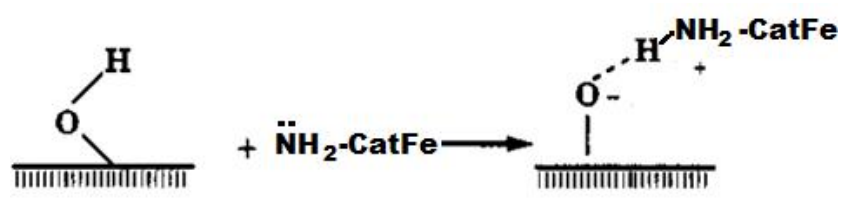

$\mathrm{I}-\mathrm{OH}=\mathrm{OH}$ group on the silica surface; $\mathrm{CatFe}=$ Iron catalyst

Fig. 1. Schematic representation of the formation of the ionic interaction between the silica surface and the catalyst

In the determination of the catalyst that does not contain amine group, because it is a physical adsorption (physisorption), leaching problems can occur during the polymerization, that is, the catalytic site can migrate to the reaction medium and the homogeneous reaction occurs. Hence, there is a need for the use of catalysts containing a functional group which produces a stronger interaction on the surface of the support. On the other hand, in the fixation of the functionalized catalyst (with $\mathrm{NH}_{2}$ group), 
the chemisorption will take place in the silica generating a species containing an ionic interaction of type $\mathrm{ONH}_{3}{ }^{+}$ (represented in 0).

Despite this new possibility of solving the catalyst leach problem by promoting a stronger interaction between support and catalytic complex, problems such as the difficulty of monomers access to the active site caused by the stereo impediment of the silica pores still must be solved. Thus, amine group was used to promote the selfspacing of the catalyst, minimizing the influence of the support surface.

\subsection{Polymerization Experiments}

All polymerization reactions were performed in a 11 Büchi glass reactor equipped with a mechanical stirrer, connected to a thermostatic system. In a typical polymerization experiment, the autoclave was charged with $100 \mathrm{ml}$ of toluene. The appropriate amount of the complex and MAO was introduced at the temperature of $323 \mathrm{~K}$. The mechanical stirrer was run with $600 \mathrm{rpm}$ for all experiments to avoid diffusion-controlled polymerization reactions. The polymerization conducted in toluene at $323 \mathrm{~K}$, ethylene pressure of $4 \cdot 10^{5} \mathrm{~Pa}$ and $\mathrm{Al} / \mathrm{Fe}=2000 . \mathrm{Al} / \mathrm{Fe}$ was varied by decreasing the amount of $\mathrm{Fe}$ catalyst in the polymerization medium. After the desired polymerization time $(60 \mathrm{~min})$, the polymerization was stopped by quenching with ethanol containing $5 \% \mathrm{HCl}$. Polymers were dried overnight at $333 \mathrm{~K}$, washed with $5 \% \mathrm{HCl}$ in ethanol solution and after that with methanol for several times until total clean of the supernatant and dried again to constant weight.

Catalytic activity (C.A.) was determined using Eq. (1) [14]:

$$
\text { C.A. }=\frac{\text { Yield }}{(\text { molFe }) \cdot(\mathrm{molE}) \cdot t}
$$

where Yield is an amount of obtained polyethylene, $\mathrm{kg}$; molFe is an amount of catalyst, mol; molE is an amount of ethylene in the reaction medium $(0.0135 \mathrm{~mol})$ and $t$ is a polymerization time, $\mathrm{h}$.

\subsection{Heterogeneous Polymerizations}

The polymerizations were carried out maintaining the same experimental conditions of the homogeneous polymerization system but containing $100 \mathrm{mg}$ of silica to obey the same molar ratio $\mathrm{Al} / \mathrm{Metal}$. It is interesting to remember that in homogeneous polymerizations the catalyst is added in the reaction medium as a solution in toluene, while in the heterogeneous the catalyst enters the polymerization medium as a suspension in the same solvent.

\subsection{Characterizations}

Fourier transform infrared spectroscopy (FTIR) was used to follow the chemical modifications occurring at each treatment step received by the carrier.
These modifications can be observed mainly by the reduction of the absorption band in the region of $3740 \mathrm{~cm}^{-1}$, referring to the non-associated (free) silanol groups $(\mathrm{Si}-\mathrm{OH})$ after the heat treatment of the material. These residual groups were subsequently used to fix the iron complex during impregnation, when the band at $3740 \mathrm{~cm}^{-1}$ tended to disappear. Spectra were obtained in the range of $4500-400 \mathrm{~cm}^{-1}$.

Supports were characterized by the liquid $\mathrm{N}_{2}$ physisorption technique and the Braunauer-Emmett-Teller (BET) equation was used to measure the external area (specific surface area) of the solids by the adsorption measurement of an inert gas $\left(\mathrm{N}_{2}\right)$ by the surface of these solids. In the BET equation (Eq. (2) described below), $V_{A}$ represents the gas volume under the normal conditions of temperature and pressure (CNTP) adsorbed at $p$ pressure; $V_{m}$ is the gas volume also in the CNTP adsorbed when the entire surface is covered by a monolayer and $c$ represents a constant.

$$
\frac{p_{A}}{V_{A}\left(p_{A_{0}}-p_{A}\right)}=\frac{1}{c \cdot V_{m}}+\frac{(c-1) \cdot p_{A}}{V \cdot c \cdot p_{A_{1}}}
$$

The adsorption and desorption's isotherms of $\mathrm{N}_{2}$ at $77 \mathrm{~K}$ were used as Micromeritics ASAP2020 equipment. Prior to measurements, samples were pretreated at $573 \mathrm{~K}$ for $12 \mathrm{~h}$ under vacuum.

Fourier transform infrared absorption spectroscopy (FTIR) analysis was also used to follow the chemical modifications occurring at each treatment step received by the carrier. These modifications can be observed mainly through the reduction of the absorption band in the region of $3740 \mathrm{~cm}^{-1}$, referring to the appearance of nonassociated (free) silanol groups $(\mathrm{Si}-\mathrm{OH})$ after the heat treatment of the material. These residual groups were later used to fix the iron complex during impregnation, when the band at $3740 \mathrm{~cm}^{-1}$ tended to disappear. The spectra were obtained in the range of $4500-400 \mathrm{~cm}^{-1}$.

The materials produced were characterized by Differential Scanning Calorimetry (DSC), Thermogravimetric Analysis (TGA), X-Ray Diffraction Analysis (XRD), Fourier Transform Infrared Spectroscopy (FTIR), bulk density and Scanning Electron Microscopy (SEM).

\section{Results and Discussion}

\subsection{Important Aspects from the Supported Catalyst}

An important way to synthesize heterogeneous catalysts is the understanding of the reactivity of a support surface towards reactive inorganic species. Metal oxide supports are terminated by surface $\mathrm{MS}-\mathrm{OH}$ and MS-O-MS groups. The types and densities of these groups can be modified by thermal treatment under vacuum. 
In the heterogeneous systems, a catalyst-containing toluene solution $(0.005 \mathrm{mmol}$ concentration) was added to the support (100 mg silica) and stirred for $12 \mathrm{~h}$. The disappearance of catalyst color in the solvent was observed in all systems, indicating that catalyst was completely adsorbed on the carrier. At first, the reaction between the complex and the silica could promote the formation of chemical bond between the $\mathrm{OH}$-groups of silica and $\mathrm{NH}_{2}$ groups of the catalyst $(\mathrm{C} 1$ and $\mathrm{C} 4)$.

As for the catalyst architecture, it is believed that the binder in the catalyst $\mathrm{C} 1$ that presents volume to the groups attached to the nitrogen could avoid the chain transfer reactions, thus obtaining a catalyst with high activity and producing polyethylene with high molar masses.

The $-\mathrm{NH}_{2}$ group at the end of the $\mathrm{Cl}$ and $\mathrm{C} 4$ complexes were employed to promote the fixation on the silica surface, avoiding catalyst leach during the polymerization of ethylene. In addition, the support could promote a physical barrier minimizing lateral reactions, even in the absence of substituents at the ortho position of the phenyl rings near the metal site.

The C2 catalyst was used to compare the performance of its iron catalyst in homogeneous and supported systems. This binder does not have the $-\mathrm{NH}_{2}$ group, and it is expected that there will be no fixation of the catalyst on the silica in a manner that prevents its leaching.

According to Knoke et al. [15], the silica fragments during the polymerization starting from a spherical particle size of approximately $50 \mu \mathrm{m}$ to fragments of about $10 \mathrm{~nm}$ due to the hydraulic forces of the polymer produced inside the pores. These very fine fragments of silica in small concentrations do not influence the properties of the product and thus, there is no need to remove them. In addition, silica exhibits chemical inertia and elevated temperature stability; it can be synthesized with pore sizes, surface areas and varied pore volumes and is also a relatively economical carrier.

The specific surface area, volume and pore diameter of the silica used as support for the catalysts in the heterogeneous systems were determined by the methods of Braunauer-Emmett-Teller (BET) and Barret-
Joyner-Halenda (BJH), respectively, and are described in Table 1.

It was observed that the specific surface did not change after the calcination or after the fixation of the complexes $\mathrm{C} 1$ and $\mathrm{C} 2$ on its surface, due to the low impregnated content. However, pore size and diameter decreased after calcination treatment and decreased further with catalyst immobilization [16]. The decrease in these values indicates that the catalyst anchorage in the carrier was successful [17].

The chemical properties of silica are mainly regulated by the presence of silanol groups on their surface, which can be changed with suitable heat treatments to enable the hydroxylated surface to be desorbed and the number of hydroxyl groups decreases continuously with increasing temperature. Fig. 2 shows the FTIR spectra of the silica before (a) and after (b) the heat treatment (calcination), in which the thermally induced change in the silica surface groups (from silanol to siloxane) is confirmed by the very sharp decrease of the band at $3740 \mathrm{~cm}^{-1}$, which is still present in the calcined silica. In the spectrum of the supported catalyst $\mathrm{sC} 1$, bands related to the impregnated complex appeared (Fig. 2c).

\subsection{Polymerization with sC1, sC2 and sC4 Supported Systems}

Immobilized catalysts $\mathrm{C} 1, \mathrm{C} 2$ and $\mathrm{C} 4$ were active in the polymerization of ethylene. The difference in catalyst structure, reaction conditions, and yield obtained in the ethylene polymerization and the catalytic activity were compared to the corresponding homogeneous systems in Table 2. To explain all these observations, we must consider both steric and electronic effects in the catalyst.

Supported systems generated catalytic activities lower than their analogous homogeneous catalysts. It can also be mentioned that, analogously to the homogeneous catalysts, the supported systems $\mathrm{C} 1$ and $\mathrm{C} 2$ obtained greater performance than the $\mathrm{C} 4$ catalyst [14].

One reason for the small catalyst activity of the supported catalyst could be the significant steric hindrance around the active site due to the huge silica surface [18].

Table 1

Textural analysis of the catalysts by the methods of Braunauer-Emmett-Teller (BET) and Barret-Joyner-Halenda (BJH)

\begin{tabular}{|c|c|c|c|}
\hline Catalyst & Specific surface area, $\mathrm{m}^{2} / \mathrm{g}$ & Volume of pores, $\mathrm{cm}^{3} / \mathrm{g}$ & Pore diameter, $\AA$ \\
\hline Silica & 433 & 2.66 & 240 \\
\hline Calcinated silica & 427 & 2.58 & 239 \\
\hline $\mathrm{sC} 1$ & 433 & 2.33 & 210 \\
\hline $\mathrm{sC2}$ & 427 & 2.28 & 209 \\
\hline
\end{tabular}




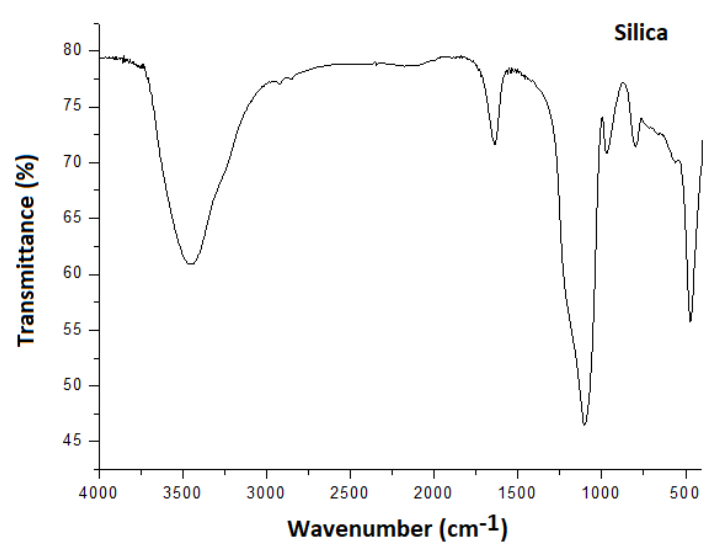

a)

Fig. 2. Silica before(a) and after calcination (b), silica after impregnation with $\mathrm{C} 1$ (c)

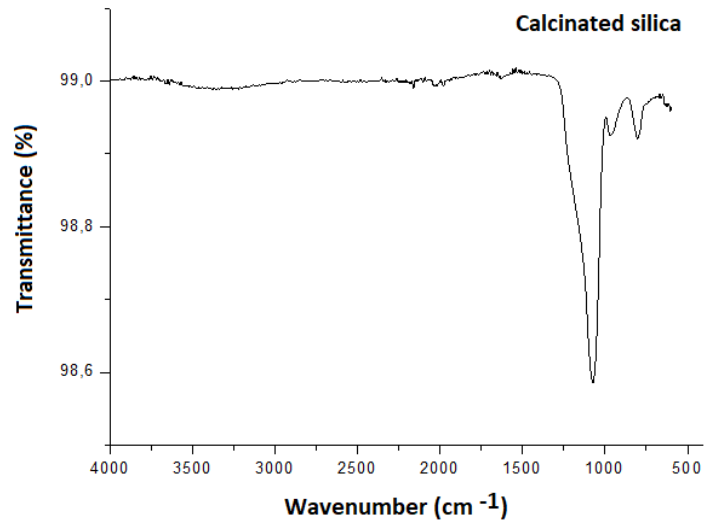

b)

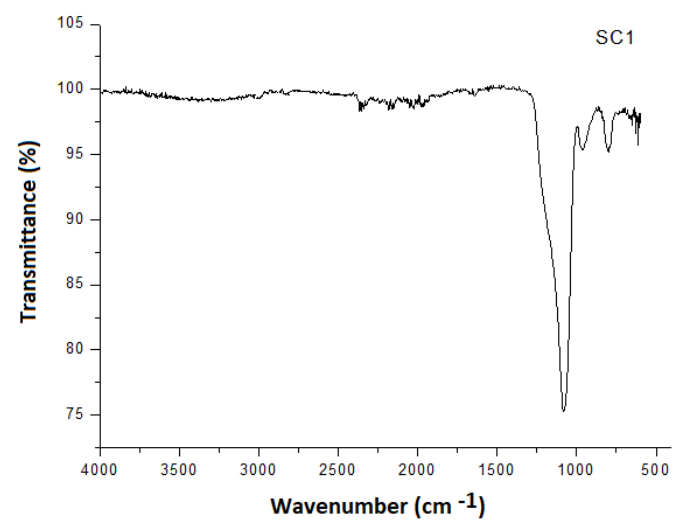

c)

Table 2

Polymerizations conducted with $\mathrm{C} 1, \mathrm{C} 2$ and $\mathrm{C} 4$ catalysts

in both homogeneous (homog.) and supported (sup.) systems

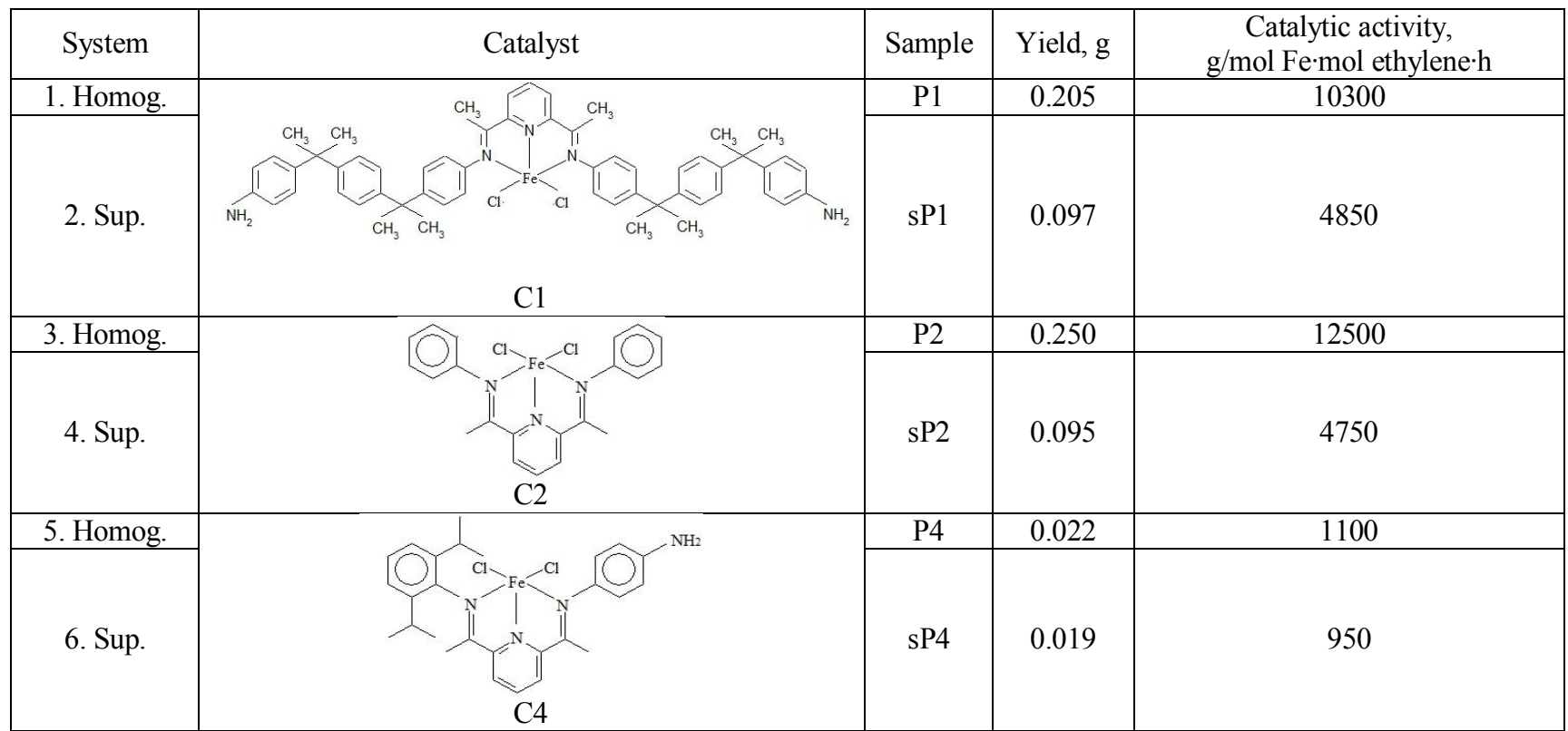

Polymerization conditions: $100 \mathrm{ml}$ toluene, $323 \mathrm{~K}, 4.10^{5} \mathrm{~Pa}$ of ethylene and the amount of catalyst $\mathrm{Fe}$ is $0.005 \mathrm{mmol}$. Supported system: $\mathrm{Fe}=0.005 \mathrm{mmol}$; silica $=100 \mathrm{mg}$ 


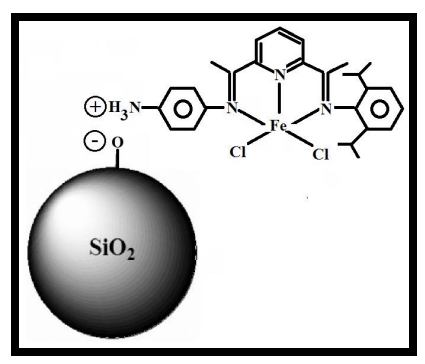

a)

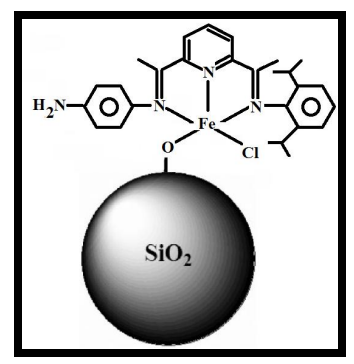

b)

Fig. 3. Structures proposed for the C4 complex supported on silica, active (a) and inactive (b)

In fact, Britovsek et al. [19] has proved that the catalytic intermediates formed from the precursors containing pyridyldimine ligands are more readily deactivated through interaction with alkylaluminium reagents if they do not have sufficient amount of steric mass in the aryl ring but in this work, despite bulky binders, the spacer groups presented in the catalyst do not seem to contribute to an easy evaluation of the active center. As we see, increasing productivity is not an easy task when dealing with supported catalysts because they have many physical and chemical effects that can influence catalytic performance.

For example, direct reaction of a surface hydroxyl group on silica with a transition metal precatalyst should generally be avoided. On the other hand, the use of surface hydroxyl groups to anchor methylaluminoxane can have the advantage of preferential reaction of $\mathrm{Si}-\mathrm{OH}$ with the AlMe3 present in MAO [20].

Fig. 3 shows the proposed structures for the supported silica catalysts, where the $\mathrm{NH}_{2}$ group on the catalyst can form a bond with the $\mathrm{OH}$ groups on the surface of the silica, thus obtaining an active site (0a) that does not undergo leaching to the reaction medium. However, there was a decrease in the catalytic activity; it is possible that a part of the iron sites has been deactivated because it reacted with the hydroxyls of silica groups of the silica, which acts as Brønsted acids.

This reaction could form the structure proposed in $0 \mathrm{~b}$. In this structure, iron is directly bound to the oxygen and activation by the MAO is not possible, because their orbitals are occupied, barring the coordination with the monomer, even after alkylation (chlorine substitution).

Physical effects can play a significant role in limiting the productivity of immobilized catalysts, particularly in ethylene polymerization using supports with low friability, when polymer formation in the pores of an unfragmented catalyst can lead to a diffusion limitation. It is important that mechanical strength of the catalyst particle is high enough to prevent disintegration, but low enough to allow progressive expansion as polymerization proceeds. High support porosity and the presence of relatively large pore radii aid monomer diffusion in ethylene polymerization, leading to regular particle growth [20-21].

Similar catalyst has been studied in the literature [22]. Bis(imino)pyridyl iron complexes chemically tethered to a silica support surface were used. In the polymerization test at $2.10^{5} \mathrm{~Pa}$ ethylene pressure at room temperature, the silica-supported catalyst was activated with co-catalyst triisobutylaluminum (TIBA). PE on a milligram scale is formed as a thin film on the silica surface $\left(2 \times 2 \mathrm{~cm}^{2}\right)$. No polymer formation was observed suspended in the reaction medium.

Commonly, the catalysts containing iron metal, lead to highly linear polymer production, specifically when the catalytic sites contain ligands with aromatic rings and bulky substituents in the ortho position. These metallic sites present a tendency to broad polydispersity $\left(M_{w} / M_{n}\right)$, due to the electronic nature of the metal. In turn, the catalysts studied in this work do not present this architecture, resulting in the production of oligomers with different chain sizes, in agreement with the literature [23].

\subsection{Characterization of Materials sP1, sP2 and sP4}

After reaction with supported catalyst, the material obtained in wax form, indicating oligomer formation [24], was washed with hexane, dried and weighed for evaluation.

The polymers obtained in the polymerizations with the $\mathrm{sC} 1, \mathrm{sC} 2$ and $\mathrm{sC} 4$ catalysts of the supported systems were characterized by DSC, XRD, TGA, FTIR, bulk density measurements, and SEM.

Characterization by DSC analysis

The polymers $\mathrm{sP} 1$ and $\mathrm{sP} 2$ were analyzed by DSC and the results are shown in Table 3 and compared with the homogeneous polymers. Melting and crystallization temperatures $T_{m}$ and $T_{c}$ were lower than those obtained in the materials of the homogeneous systems, indicating a marked decrease in the crystallinity of the polyethylene obtained by the supported catalysts.

Comparing the degree of crystallinity of the polymer obtained by this family of catalysts, commonly cited as reference polymer in the literature [24], the supported polymers showed the reduction of $30 \%$. 
Table 3 lower than the polymer obtained in the homogeneous

Values of $T_{c}, T_{m}$ and $X_{c}$ obtained by DSC analysis

\begin{tabular}{|c|c|c|c|}
\hline Polymer samples & $T_{c}, \mathrm{~K}$ & $T_{m}, \mathrm{~K}$ & $X_{c}, \%$ \\
\hline $\mathrm{P} 1$ & 389 & 399 & 44.4 \\
\hline $\mathrm{sP} 1$ & 374 & 388 & 40.6 \\
\hline $\mathrm{P} 2$ & 392 & 406 & 41.8 \\
\hline $\mathrm{sP} 2$ & 373 & 387 & 16.7 \\
\hline
\end{tabular}

Characterization by X-ray diffractometry

The X-ray diffraction pattern of the polyethylene sP1 is shown in 0 . The peaks referring to the orthorhombic cell of the polyethylene crystals appear in the XRD. The polyethylene sample sP2 had no defined diffraction peak, indicating low crystallinity of the material. The polymer sample $\mathrm{sP} 4$ cannot be evaluated by $\mathrm{XRD}$ because of the low yield obtained as mentioned above.

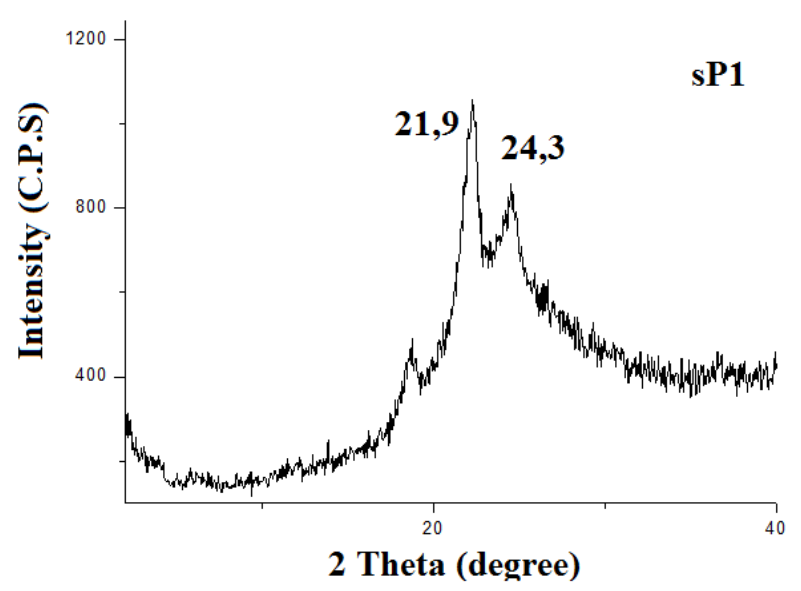

Fig. 4. Diffractogram of the polymer sP1, obtained by XRD

Characterization by thermogravimetric analysis

The results of initial thermal degradation temperature $\left(T_{\text {onset }}\right)$, the temperature of maximum degradation rate $\left(T_{\max }\right)$ as well as the residue at $973 \mathrm{~K}$ for the polyethylenes obtained by the supported catalyst systems were compared with those of PE synthesized with the homogeneous ones (Table 4). It is noticed that the content of catalytic residue is very high in the polymers obtained by supported systems, and probably refers to the presence of silica in the polymer. The degradation temperature value of the polymer $\mathrm{sP} 1$ is lower than its homogeneous counterpart, suggesting that the polyethylene obtained in the supported system is more branched and with lower molar mass than in the homogeneous one. This effect is much more evident for the polymer $\mathrm{sP} 2$, which degradation temperature is much

Table 4

Values of $\boldsymbol{T}_{\text {onset }}, \boldsymbol{T}_{\max }$ and residue obtained by TGA

\begin{tabular}{|c|c|c|c|}
\hline Polymer & $T_{\text {onset }}, \mathrm{K}$ & $T_{\max }, \mathrm{K}$ & Residue, $\%$ \\
\hline $\mathrm{P} 1$ & 729 & 751 & 1.69 \\
\hline $\mathrm{sP} 1$ & 706 & 707 & 68.8 \\
\hline $\mathrm{P} 2$ & 731 & 750 & 3.60 \\
\hline $\mathrm{sP} 2$ & 661 & 696 & 72.3 \\
\hline
\end{tabular}

Characterization by FTIR analysis

The FTIR spectrum of the SP1 polymer shows discrete bands related to polyethylene (at 2920-2850, 1486-1348 and $750-720 \mathrm{~cm}^{-1}$ ), as well as very pronounced silica bands. This shows that, due to the low catalytic activities, the silica content in the polymer was high. The graphs that characterize the material (polyethylene on silica) by FTIR are shown in 0 .

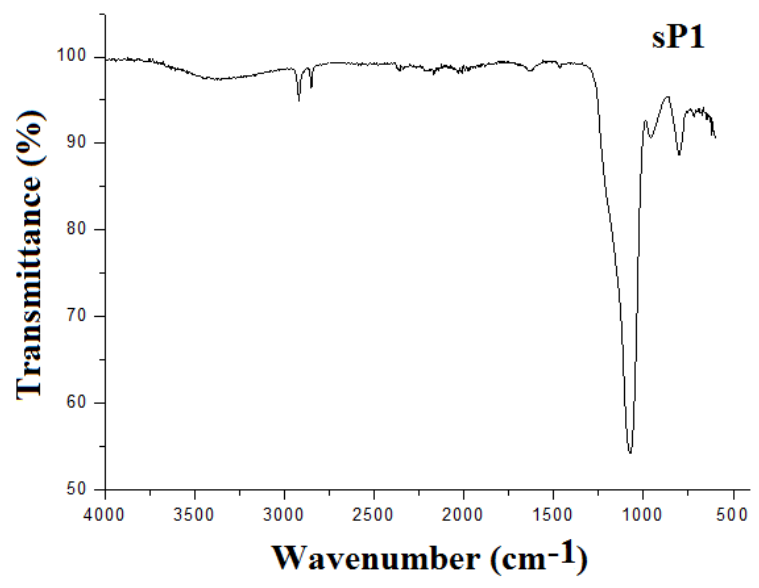

Fig. 5. FTIR spectrum of sP1 polymer produced in supported system

Bulk density measurements

Table 5 presents the bulk density $(\mathrm{g} / \mathrm{ml})$ of the synthesized polyethylene particles. The lower values of density $(0.099 \mathrm{~g} / \mathrm{ml})$ correspond to polymers with larger particle diameters and lower content of fines (particles $<120 \mu \mathrm{m}$ ), than those obtained ideally by supported systems. A slight decrease in bulk density is observed for the polymer sP1, obtained by the supported system, and a much steeper drop for the sP4. However, the sP2 particles did not vary in bulk density as compared with the polymer obtained by the homogeneous system. This indicates that the polymer particles produced by the heterogeneous polymerization with the catalysts containing $\mathrm{NH}_{2}$ groups are larger, with more voids between each other, and consequently with lower the bulk density, showing that in fact the methodology of heterogenization applied in this work reached the objective of reducing the production of 
"fines" on the reactor. For the catalyst $\mathrm{sC} 2$, this did not occur, possibly due to the absence of functional groups in its structure to chemically bond the complex to the silica surface, and thus allowing catalyst leaching.

\section{Table 5}

Bulk density values of polyethylene samples

\begin{tabular}{|c|c|}
\hline Polyethylene samples & Bulk density, g/ml \\
\hline P1 & 0.103 \\
\hline sP1 & 0.099 \\
\hline P2 & 0.106 \\
\hline sP2 & 0.107 \\
\hline P4 & 0.164 \\
\hline SP4 & 0.143 \\
\hline
\end{tabular}

Notes: $323 \mathrm{~K}, 4.10^{5} \mathrm{~Pa},[\mathrm{Al}] /[\mathrm{Fe}]=2000[\mathrm{Fe}]=0.005 \mathrm{mmol}$

Characterization by SEM analysis

Finally, in view of the importance of polymer morphology for industrial processing, we seek to investigate morphological control launched by our catalysts, and the resulting polymers. Fig. 6 shows scanning electron microscopy (SEM) microphotographs of the silica carrier (a), the polymers $\mathrm{P} 1$ (b) and sP1 (c).

For the polymer obtained by the homogeneous system P1, the presence of irregular particles with dimensions of $1-2 \mathrm{~mm}$ and small fragments around $100 \mu \mathrm{m}$ can be observed in Fig. 6b. For the sP1 polymer obtained with the supported catalyst (Fig. 6c), spherical particles having diameters of approximately $300 \mu \mathrm{m}$, noticeably larger than the free silica particles $(200 \mu \mathrm{m})$ of polymer material are observed in Fig. 6a.

Unlike the particles shown in sP1 samples, that have regular shape with spherical tendencies, observed in larger enlargements in 0 , in the samples of $\mathrm{P} 1$, the presence of particles with an irregular morphological profile and dimensions smaller than $100 \mu \mathrm{m}$ is also observed. This shows some morphological control in this supported system. In the sP1 samples at higher magnification (0b), filled pores can be observed on the surface of the silica, indicating the fixation of the catalyst in the innermost regions of the support.

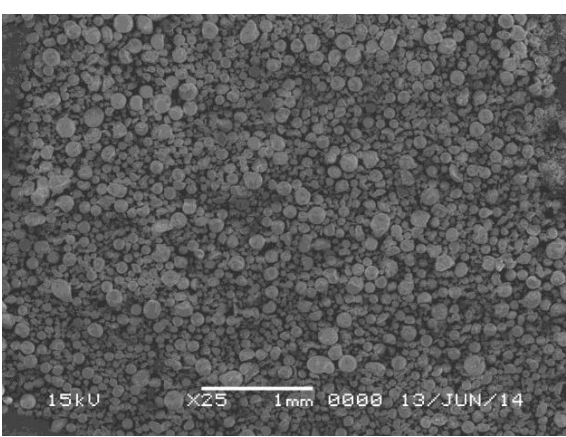

a)

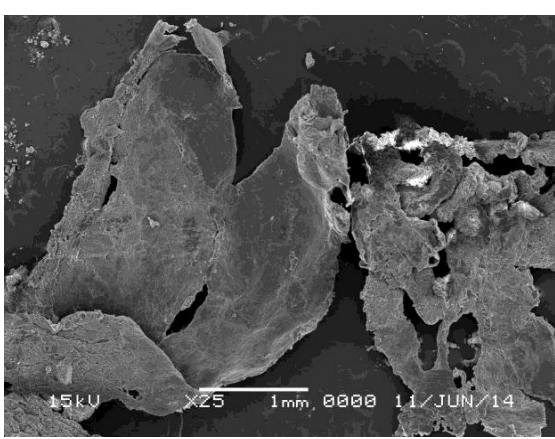

b)

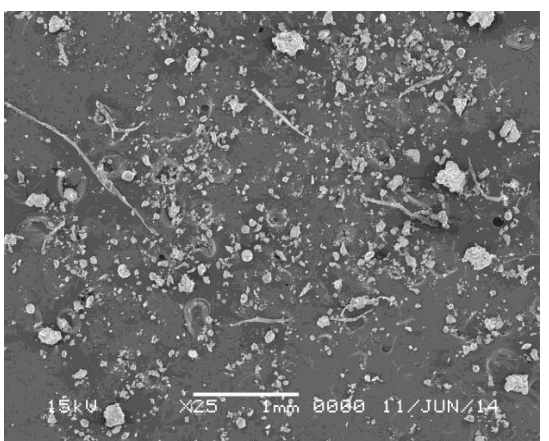

c)

Fig. 6. SEM image of silica-support (a), polymer P1 (b) and polymer sP1 (c)

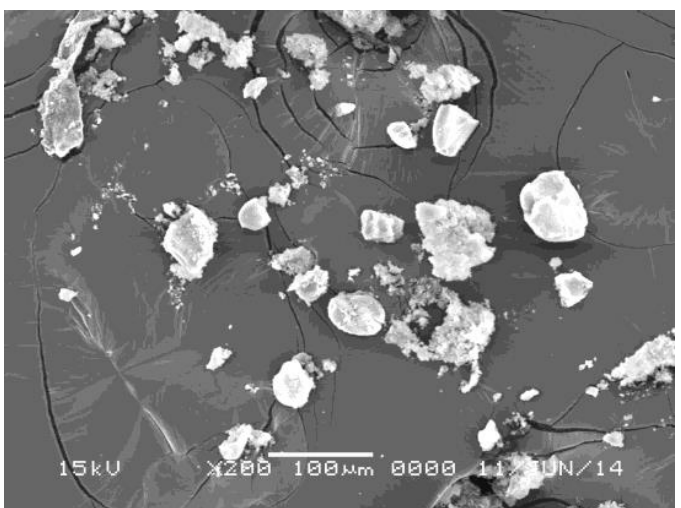

a)

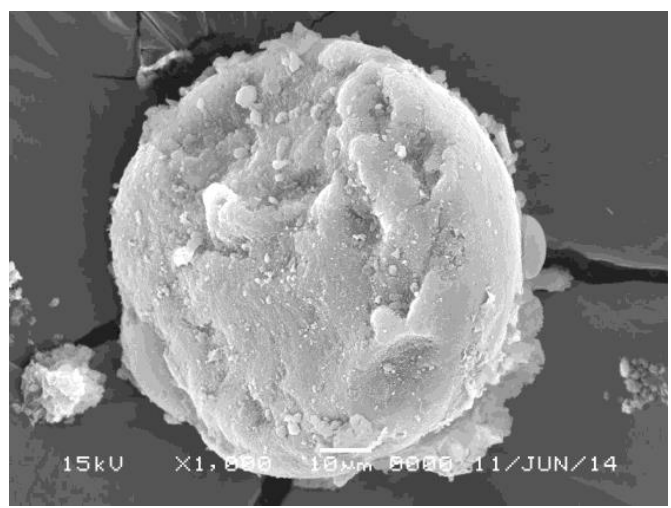

b)

Fig. 7. SEM image of the silica and particle morphology of polymer sP1 obtained by ethylene polymerization on MAO-activated $\mathrm{sC} 1$. Magnification of $200 \times$ (a) and $1000 \times$ (b) 


\section{Conclusions}

Supported systems with bis(imino) pyridine-based iron complexes on the silica were characterized, used in he polymerization of ethylene and compared with their analogous homogeneous systems.

The heterogeneous polymerization of three different iron complexes (with and without free- $\mathrm{NH}_{2}$ on the ligands) was conducted in toluene at $323 \mathrm{~K}$, ethylene pressure of $4.10^{5} \mathrm{~Pa}$ and $\mathrm{Al} / \mathrm{Fe}=2000$, using silica supported catalysts $(0.05 \mathrm{mmol} \mathrm{Fe} / \mathrm{g}$ silica $)$, where these complexes were directly immobilized on silica surface.

The activities of the supported catalysts in ethylene polymerization were lower than those of the corresponding homogeneous systems, indicating that despite having active catalytic sites, some are affected by the supporting reaction conditions, suffering deactivation.

The $\mathrm{NH}_{2}$ group on the $\mathrm{C} 1$ and $\mathrm{C} 4$ catalysts exerted a negative influence on the performance of the homogeneous catalyst. Although the group did not affect the performance of the homogeneous system, it resulted in less activity in the supported systems. This paper showed the proposed structures for the supported silica catalysts.

The absence of substituent groups (ortho position of the phenyl ring) near the sites was not satisfied by the stereo impedance of bulky binders or the silica surface as carrier, which caused the catalytic activity to decrease.

The catalyst $\mathrm{C} 1$ was considered the one with the best performance, because it presented good catalytic activity not only in the homogeneous system but also in the systems supported on silica and, due to the chemical bonding between the functionalized complex and the support surface, allowed obtaining particles of polyethylene SP1 with good morphology, observed in the micrographs (obtained by SEM) and in the reduction of the apparent density, compared to the particles produced by the homogeneous catalysts. FTIR bands related to polyethylene at 2920-2850, 1486-1348 and 750-720 $\mathrm{cm}^{-1}$ and other analyzes (XRD, DSC and TGA) revealed that the material produced by the heterogenous system is a branched polyethylene, with lower crystallinity and lower molar mass than the homogeneous polymer.

\section{Acknowledgments}

This work was financially supported by $\mathrm{CNPq}$ and CAPES (Brazil).

\section{References}

[1] Sturzel M., Mihan S., Mulhaupt R.: Chem. Rev., 2016, 116, 1398. https://doi.org/10.1021/acs.chemrev.5b00310
[2] Zima A., Lyakin O., Ottenbacher R. et al.: ACS Catal, 2016, 7, 60. https://doi.org/10.1021/acscatal.6b02851

[3] Wang Z. et al.: Coordin. Chem. Rev, 2018, 363, 92.

https://doi.org/10.1016/j.ccr.2018.02.016

[4] Ma Z., Sun W., Zhu N. et al.: Polym. Int., 2002, 51, 349.

https://doi.org/10.1002/pi.853

[5] Kim I., Han B., Ha C. et al.: Macromolecules, 2003, 36, 6689.

https://doi.org/10.1021/ma0347060

[6] Beaufort L., Benvenuti F., Noels A.: J. Mol. Catal. A, 2006, 260,

215. https://doi.org/10.1016/j.molcata.2006.07.010

[7] Dos Santos J., Greco P., Stedile F., Dupont J.: J. Mol. Catal. A,

2000, 154, 103. https://doi.org/10.1016/S1381-1169(99)00393-3

[8] Comito R., Fritzsching K., Sundell B. et al.: J. Am. Chem. Soc.

2016, 138, 10232. https://doi.org/10.1021/jacs.6b05200

[9] Heurtefeu B. et al.: Prog. Polym. Sci., 2010, 36, 89.

https://doi.org/10.1016/j.progpolymsci.2010.09.002

[10] Atiqullah M., Anantawaraskul S., Emwas A. et al.: Polym. Int., 2014, 63, 955. https://doi.org/10.1002/pi.4587

[11] Marques M., da Silva O., Coutinho A., Araujo A.: Polym. Bull., 2008, 61, 415. https://doi.org/10.1007/s00289-008-0965-Z

[12] Copéret C., Allouche F., Chan K. et al.: Angew. Chem. Int. Ed., 2018, 57, 6398. https://doi.org/10.1002/anie.201702387

[13] Lee J., Yim J., Jeon J., Ko Y.: Catal. Today, 2012, 185, 175.

https://doi.org/10.1016/j.cattod.2011.12.003

[14] Cordeiro S., Pereira L., Simões M., Marques M.: Chem. Chem.

Technol., 2016, 10, 413.

[15] McKittrick M.: Single-site olefin polymerization catalysts via the molecular design of porous silica, $\mathrm{PhD}$ in Chemical and Biomolecular Engineering, Georgia Institute of Technology, 2005.

[16] Lee D., Yoon K., J. Mol. Catal. A: Chem. 2014, 1386, 120.

https://doi.org/10.1016/j.molcata.2014.01.015

[17] Lee D., Yoon K., Noh S.: Macromol. Rapid. Commun., 1997, 18, 639. https://doi.org/10.1002/marc.1997.030180510

[18] Britovsek G., Mastroianni S., Solan G. et al.: Chem. Eur. J., 2000, 6, 2221. https://doi.org/10.1002/1521-

3765(20000616)6:12<2221::AID-CHEM2221>3.0.CO;2-U

[19] Severn J., Chadwick J.: Dalton Trans., 2013, 42, 8979.

https://doi.org/10.1039/C3DT33098B

[20] Hammawa H., Wanke S.: J. Appl. Polym. Sci., 2007, 104, 514. https://doi.org/10.1002/app.25527

[21] Han W., Müller C., Vogt D. et al.: Macromol. Rapid. Commun. 2006, 27, 279. https://doi.org/10.1002/marc.200500701

[22] Zhang W., Ye J., Jiang B. et al.: Macromol. React. Eng., 2018,

12, 1700061. https://doi.org/10.1002/mren.201700061

[23] Yoshida-Hirahara M., Fujiwara S., Kurokawa H.: Mod. Res.

Catal., 2017, 6, 100. https://doi.org/10.4236/mrc.2017.62008

[24] Bryliakov K., Semikolenova N., Zudin V. et al.: Catal.

Commun., 2004, 5, 45. https://doi.org/10.1016/j.catcom.2003.11.010

Received: October 31, 2018 / Revised: November 28, 2018 / Accepted: April 12, 2019

\section{ХАРАКТЕРИСТИКА КАТАЛІЗАТОРА НА ОСНОВІ БІС(ІМІНО)ПІРИДИНОВОГО ЗАЛІЗА ДЛЯ ГЕТЕРОГЕННОЇ ПОЛІМЕРИЗАЦІЇ ЕТИЛЕНУ}

\footnotetext{
Анотація. Синтезовано та встановлено характеритики постметалоченових комплексів на основі біс(іміно) піридинового заліза (носій - кремнезем) з аміногрупами для
} 
полімеризації етилену. Виявлено, щзо взаємодія ицих комплексів і метилалюмоксана приводить до утворення активних сполук при гетерогенній полімеризації етилену. Відсутність замісників у орто-положенні фенильних кілець поблизу металу не компенсується стеричними перешкодами на поверхні кремнезему, негативно впливаючи на каталітичну активність $i$ молярну масу отриманого полімеру. Доведено, щзо каталізатор C1, з найбільи об'ємним лігандом, має найвищу каталітичну активність не тільки в гомогенній системі, але $i$ в системах з носієм, внаслідок хімічного зв'язку між функиіоналізованим комплексом і поверхнею носія, щзо приводить до утворення поліетиленових частинок з хорошою морфологією, сферичною поверхнею, заповненими порами $i$ зменшення насипної щцільності порівняно з частинками, щуо утворюються за допомогою гомогенного каталізатора.

Ключові слова: полімеризація етилену, каталізатор на носії, кремнезем, біс(іміно)піридиновий каталізатор. 